Pediat. Res. 2: 172-178 (1968)

Cholesterol fatty acids

erythrocyte lipid phospholipid

erythrocytes

\title{
Erythrocyte Lipids in the Neonate
}

\author{
R.C.NeErhouT ${ }^{[47]}$ \\ Department of Pediatrics, University of California School of Medicine, Los Angeles, California, USA
}

\begin{abstract}
Extract
The lipid composition has been characterized in erythrocytes obtained from the cord blood of fullterm normal infants. There is an increase in total lipid, lipid phosphorous and cholesterol per cell (total lipid $=6.45 \times 10^{-10} \mathrm{mg}$; Lipid $\mathrm{P}=1.54 \times 10^{-11} \mathrm{mg}$; cholesterol $=1.79 \times 10^{-10} \mathrm{mg}$ ) when compared with adult controls (total lipid $=5.07 \times 10^{-10} \mathrm{mg}$; Lipid $\mathrm{P}=1.22 \times 10^{-11} \mathrm{mg}$; cholesterol $=$ $1.33 \times 10^{-10} \mathrm{mg}$ ). Despite the increased lipid content, the percentages of total lipid comprised by lipid phosphorous and cholesterol are similar to those found in the adult $(\mathrm{P}=2.40 \%$ of total lipid in infants, $2.41 \%$ in adults: cholesterol $=27.1 \%$ of total lipid in infants, $26.0 \%$ in adults). Phospholipid fractionation shows minor variations between the two groups. Cord blood erythrocyte phospholipid has $1.0 \%$ lysolecithin, $26.0 \%$ sphingomyelin, $27.7 \%$ phosphatidylcholine, $15.2 \%$ combined phosphatidylserine and phosphatidylinositol, and $29.1 \%$ phosphatidylethanolamine. Adult erythrocyte phospholipid has $1.2 \%$ lysolecithin, $24.1 \%$ sphingomyelin, $29.5 \%$ phosphatidylcholine, $13.1 \%$ combined phosphatidylserine and phosphatidylinositol and $31.2 \%$ phosphatidylethanolamine. Phospholipid fatty acid patterns in cord blood erythrocytes show an increased percentage of palmitic acid (cord = $21.3 \%$, adult $=17.0 \%$ ), stearic acid (cord $=16.3 \%$, adult $=15.3 \%$ ) arachidonic acid (cord $=$ $19.6 \%$, adult $=17.4 \%$ ) and combined 22 and 24 carbon fatty acids (cord $=17.6 \%$, adult $=16.3 \%$ ) associated with decreased percentages of oleic acid (cord $=11.9 \%$, adult $=14.6 \%$ ) and linoleic acid $($ cord $=3.4 \%$, adult $=10.9 \%)$.
\end{abstract}

\section{Speculation}

The erythrocyte lipids of the newborn show deviations from the adult pattern which may have adaptive value for intrauterine life. These same adaptations may render the cell more vulnerable to oxidative damage in postnatal life.

\section{Introduction}

The lipid composition of erythrocytes has recently become a matter of great interest. Studies have shown that the red cell lipid is composed almost entirely of free cholesterol and phospholipid [32, 40]. The minute amounts of cholesterol esters, the roughly equivalent proportion of phosphatidylcholine and phosphatidylethanolamine and the presence of phosphatidylserine imprint a pattern of erythrocyte lipid in the adult clearly different from that of the plasma-environment. Adult plasma has two-thirds of the cholesterol in the esterified form, a proportion of phosphatidylcholine ten times that of phosphatidylethanolamine and lacks 
phosphatidylserine [29, 31]. Despite the rather divergent lipid composition of the erythrocyte and its plasma environment, there is little evidence of de novo synthesis of lipid by the red cell [19], and in vitro evidence suggests that a major pathway for replacement of red cell chollesterol [3], phospholipid [33], and phospholipid fatty acid [21] is through interchange with plasma lipids. An abnormality of erythrocyte lipid composition in association with an abnormal plasma environment has been clearly demonstrated in patients with abetalipoproteinemia [30, 39]. The characteristic hematologic abnormality seen in this disorder is the presence of small contracted red cells (acanthocytes). A small percentage of similarly shaped cells has been noted as a normal finding in full-term and premature infants and may constitute up to $50 \%$ of the erythrocytes of certain premature infants with infantile pyknocytosis [36]. Cord blood plasma has been shown to differ markedly from adult plasma with lower levels of cholesterol, phospholipid and both high and low density lipoproteins $[6,8,9,42]$. The present study was undertaken to define the lipid composition of cord blood erythrocytes which have been exposed in vivo to plasma with the lowered lipid content characteristic of cord blood.

Previous reports utilizing smaller numbers of patients have shown a cord blood erythrocyte membrane lipid composition varying in several parameters from adult cells $[4,9,13,30]$.

\section{Material}

Cord blood samples were collected from 42 full-term uncomplicated deliveries. There were 24 female and 18 male infants in the study. Birth weights ranged from $2520 \mathrm{~g}$ to $4500 \mathrm{~g}$. The group included 32 Gaucasian, 8 Negro, and 2 Oriental infants. All infants were free of obvious pathology and no infants with maternalfetal $\mathrm{Rh}$ incompatibility were utilized. The presence of maternal-fetal ABO incompatibility was not tested, but no patient showed clinical evidence of this. The course of all infants while in the nursery was uneventful.

\section{Methods}

Blood samples were collected in disodium EDTA, centrifuged at $4^{\circ}$ and the plasma and buffy coat removed. Cells were washed 2-3 times with three volumes of $0.9 \% \mathrm{NaCl}$ until the supernatant was clear. A suspension of red cells in physiologic saline was made with a hematocrit ranging from $65-75 \%$. Aliquots were taken for hematocrit determination and cell counting using a Coulter Model B electronic particle counter.
Stromal lipid extraction was performed by a modification of the method of FARQUHAR [12]. Two ml aliquots of the cell suspension were added to $14 \mathrm{ml}$ of redistilled $\mathrm{MeOH}$ containing $0.2 \mathrm{ml}$ of $0.1 \%$ hydroquinone. Flasks were flushed with nitrogen and sealed for 10 minutes. Clumps of stroma were broken and $28 \mathrm{ml}$ chloroform was added with mixing. Nitrogen was bubbled through the mixture, the flask flushed with nitrogen and sealed. Extraction was carried out at room temperature for 90 minutes with continuous shaking. The mixture was filtered through a coarse sintered glass funnel into a separatory funnel and the filter cake returned to the extraction flask. Reextraction was performed in $15 \mathrm{ml}$ chloroform: methanol $2: 1(\mathrm{v} / \mathrm{v})$ with shaking for one hour. The extraction mixture was again filtered into the separatory funnel as above. Partitioning was performed by adding $14 \mathrm{ml}$ of $0.58 \%$ $\mathrm{NaCl}$ (containing $25 \mu \mathrm{g} \mathrm{EDTA} / \mathrm{ml}$ ), flushing with nitrogen and shaking. The samples were placed in a freezer at $-20^{\circ}$ for 2 hours, at which time the phases were clearly separated. After returning to room temperature, the upper phase was removed with suctioning and the interphase washed with blank upper phase (methanol:0.58\% NaCl: chloroform $47: 48: 3 \mathrm{v} / \mathrm{v}$ ) until clear. The lower phase was transferred to a flask, flushed with nitrogen, and dried under suction in a rotary evaporator at $32^{\circ}$. Dried lipids were dissolved in petroleum ether and redried in vacuo twice to assure dryness. Lipids were then dissolved in petroleum ether, transferred with washing to a $10 \mathrm{ml}$ volumetric flask and made to volume. Aliquots of the total lipid extract were taken for the following determinations:

Total lipid. Determined gravimetrically after evaporation of solvent and drying overnight in a dessicator jar containing anhydrous $\mathrm{CaSO}_{4}$.

Total cholesterol. The aliquot for total lipid was redissolved and total cholesterol determined by the method of Chiamori and Henry [7].

Lipid phosphorous. Determined by the method of BARTLETT [2].

Phospholipid fractionation. Samples were separated into individual phospholipids by thin layer chromatography using a modification of the method of SkIPSKI et al. [35]. Basic plates of silica gel $\mathrm{H}$ suspended in 0.10 $\mathrm{M}$ sodium carbonate were run in a solvent system of chloroform:methanol: glacial acetic acid: water (50: $25: 8: 4)$. Lipid spots were localized by iodine vapor and identified by comparison with purified phospholipid standards [43]. Phosphorous content was determined by the method of Parker and Peterson [28], modified by allowing digestion in concentrated sulfuric acid overnight.

Phospholipid fatty acids. Phospholipids were separated from nonphospholipids by silicic acid column chromatography according to the method of WAYs and HANA- 
HAN [40]. Fatty acids were methylated under nitrogen in $\mathrm{H}_{2} \mathrm{SO}_{4}$ and methanol as described by WAys et al. [39]. Gas chromatography was performed on 6-foot diethylene glycol succinate columns in a Perkin-Elmer Model 810 chromatogram with hydrogen flame detector. Fatty acids were identified by comparison with known standards [44] and published retention times [1]. Aldehydes were identified by the method of FARQUHAR [11]. Peak area was proportional to weight for methyl esters using the flame detector based on assay of quantitative standard mixtures [44] as has been previously noted [40]. Statistical analysis of the group data was performed utilizing the group mean and standard deviation. Comparison of adult and fetal groups was made by the standard t-test analysis.

\section{Results}

Assays of total lipid, lipid phosphorous and cholesterol were performed on 42 cord blood samples. The results are shown in table I and are compared with data obtained from studies on a group of 21 normal adult controls. The values for adult controls are in general agreement with published series [12, 32, 38, 40]. It will be noted in the controls that values for total lipid, lipid phosphorous and cholesterol, when calculated on the basis of $\mathrm{mg}$ per $100 \mathrm{ml}$ packed cells, are $10^{12}$ times larger than when calculated on a mg per cell basis. This reflects the fact that the mean corpuscular volume (MCV) of washed adult erythrocytes is 100 micron $^{3}$. Since the MCV of washed cord blood cells was 120 micron $^{3}$, the relative macrocytosis is reflected in larger values when calculated on a mg per cell basis than when calculated on the basis of $\mathrm{mg}$ per $100 \mathrm{ml}$ packed cells. The values for total lipid, lipid phosphorous and cholesterol are all significantly increased ( $p$ $<0.01$ ) over their comparable values in adult cells whether calculated per cell or per $100 \mathrm{ml}$ packed cells. Several points of comparison can be made between these data and that of Crowley et al. [9]. Both series show washed fetal cells to have a similar MCV (present series: $\mathrm{MCV}=120$; Crowley et al.: $\mathrm{MCV}=121$ ) and both show a similar increase in total lipid per cell in fetal cells as compared to adult cells (present series: fetal cells total lipid $=27.2 \%$ higher than adult; CROWlex et al. $=25.8 \%$ ). This present series shows a similar percentage of total lipid as phospholipid and cholesterol in both fetal and adult cells, while CROwLEY et al. showed a lower percentage of phospholipid (fetal cell lipid $=2.28 \%$ phosphorous; adult cell $=2.60 \%$ phosphorous) with a similar percentage of cholesterol (fetal cell lipid $=24.5 \%$ cholesterol ; adult cell lipid $=$ $25.8 \%$ cholesterol).

The percent distribution of individual erythrocyte phospholipids in 28 cord bloods and 12 adult controls is given in table II. As shown by CROwLeY et al. [9], the mean values for cord blood phospholipids give a lower percentage of phosphatidylcholine (27.7\%) and phosphatidylethanolamine $(29.1 \%)$ and a higher percentage of sphingomyelin $(26.0 \%)$ and combined phosphatidylserine and phosphatidylinositol (15.2\%) than do adult cells (phosphatidylcholine $=29.5 \%$; phosphatidylethanolamine $=31.2 \%$; sphingomyelin $=$ $24.1 \%$; phosphatidylserine and phosphatidylinositol $=13.1 \%$ ). However, only the differences in phosphatidylcholine and phosphatidylserine+phosphatidylinositol are significant at $p<0.01$, whereas Growley et al. [9] showed significant differences at this level only in the sphingomyelin and phosphatidylethanolamine fractions. Whether the statistical differences between these two series are due to differences in methodology in fractionating phospholipids or merely reflect the larger sample size in the present series is unclear. It should be noted that the percent phosphatidylethanolamine in the adult group, determined by thin layer chromatography, is higher than that reported by

Table III. Distribution of fatty acids esterified to phospholipid. Expressed as \% of total fatty acids by weight

\begin{tabular}{lrrrl}
\hline Fatty acid & \multicolumn{2}{c}{ Adult blood } & \multicolumn{2}{c}{ Cord blood } \\
& Mean & 土SD & Mean & 土SD \\
\hline $14: 0^{1}$ & 0.2 & 0.05 & 0.2 & 0.08 \\
$16:$ al & 2.0 & 0.22 & 2.0 & 0.36 \\
$16: 0$ & 17.0 & 1.21 & 21.3 & $2.38^{3}$ \\
$16: 1$ & 0.7 & 0.22 & 1.0 & 0.28 \\
$17: 0$ & 0.2 & 0.04 & 0.1 & $0.05^{3}$ \\
$18:$ al & 4.1 & 0.44 & 3.5 & $0.14^{3}$ \\
$18: 0$ & 15.3 & 0.24 & 16.3 & $0.99^{3}$ \\
$18: 1$ & 14.6 & 1.00 & 11.9 & $1.08^{3}$ \\
$18: 2$ & 10.9 & 1.19 & 3.4 & $0.55^{3}$ \\
$18: 3$ & 0.3 & 0.08 & 0.3 & 0.10 \\
$20: 2$ & 0.1 & 0.09 & 0.5 & $0.22^{3}$ \\
$20: 3$ & 1.4 & 0.23 & 2.7 & $0.59^{3}$ \\
$20: 4$ & 17.4 & 1.12 & 19.6 & $1.39^{3}$ \\
$20: 5$ & 1.2 & 0.91 & 1.0 & 0.91 \\
2 & 0.3 & 0.21 & 0.3 & 0.31 \\
$24: 0$ & 4.9 & 1.43 & 5.5 & 1.59 \\
$24: 1$ & 2.6 & 0.75 & 3.4 & $0.70^{3}$ \\
$22: 5$ & 2.5 & 0.74 & 0.8 & $0.90^{3}$ \\
$22: 6$ & 4.8 & 0.80 & 6.6 & $1.09^{3}$ \\
\hline
\end{tabular}

${ }^{1}$ See text for designation of fatty acids.

${ }^{2}$ Unidentified peak.

${ }^{3}$ Significant at $\mathrm{p}<0.01$ when compared to adult values. 
CROWLey et al. [9] who utilized silicic acid impregnated paper and column chromatography for measurement. Results similar to those in this series have been noted by others utilizing thin layer chromatography [5].

The fatty acids esterified to phospholipids from 28 cord blood samples and 16 adult controls are shown in table III. Fatty acids are identified numerically by the carbon chain length and the number of unsaturated double bonds (18:2 = 18 carbon chain $: 2$ double bonds; $18 \mathrm{al}=18$ carbon chain aldehyde). The main deviations from adult controls seen in the cord blood phospholipid fatty acids are an increased percentage of palmitic acid (16:0), stearic acid (18:0), arachidonic acid $(20: 4)$ and the longer chain fatty acids (24:0, 24:1, $22: 6)$ in association with reduced amounts of oleic acid $(18: 1)$ and linoleic acid $(18: 2)$. Similar results were noted by CROWLEY et al. [9], although absolute values differ in part due to calculations based on percent by weight rather than moles percent plus the inclusion of aldehydes in the calculations of this series.

When the study patients are divided into four groups on the basis of birth weight $(2500-2999 \mathrm{~g}=8$ patients: $3000-3499 \mathrm{~g}=21$ patients: $3500-3999 \mathrm{~g}=7$ patients, $4000-4500 \mathrm{~g}=6$ patients), there is no evidence of a consistent trend between the groups and no significant deviation from the combined group mean in any parameter studied. Similarly, separation by sex revealed no significant differences in the parameters studied.

\section{Discussion}

It would appear from the above data and that of CROWLEY et al. [9] that the lipid composition of cord blood erythrocytes has a distinctive pattern which serves to differentiate clearly these cells from adult cells. Although the total lipid content per cell is greater in cord blood than in adult blood, the relative percentage composition of phospholipid and cholesterol remains quite similar. Analysis of hemoglobin-free adult erythrocyte ghosts has demonstrated that the lipid is contained entirely in the cell membrane [10]. Although surface area measurements of the cells studied are not

Table I. Erythrocyte lipid distribution. Comparison of cord blood erythrocytes with adult blood erythrocytes

\begin{tabular}{|c|c|c|c|c|c|c|c|c|c|}
\hline & & \multicolumn{3}{|c|}{$\mathrm{mg} / \mathrm{cell}$} & \multicolumn{3}{|c|}{$\mathrm{mg} / 100 \mathrm{ml}$ cells } & \multicolumn{2}{|c|}{$\%$ of T.L. } \\
\hline & & $\begin{array}{l}\text { T.L.' } \\
\left(\times 10^{-10}\right)\end{array}$ & $\begin{array}{l}\text { P. }^{2} \\
\left(\times 10^{-11}\right)\end{array}$ & $\begin{array}{l}\text { Chol. } \\
\left(\times 10^{-10}\right)\end{array}$ & T.L. & P. & Chol. & $\% \mathrm{P}$. & \% Chol. \\
\hline \multirow[t]{2}{*}{ Adult blood } & mean & 5.07 & 1.22 & 1.33 & 507 & 12.2 & 135 & 2.41 & 26.0 \\
\hline & $\pm \mathrm{SD}$ & 0.40 & 0.10 & 0.16 & 36 & 0.64 & 9.33 & 0.11 & 2.1 \\
\hline \multirow[t]{3}{*}{ Cord blood } & mean & 6.45 & 1.54 & 1.79 & 537 & 12.9 & 148 & 2.40 & 27.1 \\
\hline & $\pm \mathrm{SD}$ & 0.48 & 0.12 & 0.16 & 36 & 0.90 & 12 & 0.17 & 2.3 \\
\hline & $\bar{p}$ & $<0.01$ & $<0.01$ & $<0.01$ & $<0.01$ & $<0.01$ & $<0.01$ & $>0.40$ & $<0.10$ \\
\hline
\end{tabular}

1 Total lipid. $\quad{ }^{2}$ Lipid phosphorous. ${ }^{3}$ Cholesterol.

Table II. Distribution of individual phosphatides in phospholipid fraction. Values expressed as \% of total lipid phosphorous

\begin{tabular}{|c|c|c|c|c|c|c|c|}
\hline & & L.L. ${ }^{1}$ & Sph. ${ }^{2}$ & P.C. ${ }^{3}$ & P.S. ${ }^{4}+$ P.I. ${ }^{5}$ & P.E. ${ }^{6}$ & P.A.? \\
\hline \multirow{2}{*}{$\overline{\text { Adult blood }}$} & mean & 1.2 & 24.1 & 29.5 & 13.1 & 31.2 & 1.0 \\
\hline & $\pm \mathrm{SD}$ & 0.37 & 2.0 & 1.4 & 1.2 & 1.5 & 0.21 \\
\hline \multirow[t]{3}{*}{ Cord blood } & mean & 1.0 & 26.0 & 27.7 & 15.2 & 29.1 & 0.9 \\
\hline & $\pm \mathrm{SD}$ & 0.10 & 2.8 & 2.1 & 1.6 & 2.9 & 0.49 \\
\hline & $\bar{p}$ & $0.01-0.02$ & $0.02-0.05$ & $<0.01$ & $<0.01$ & $0.02-0.05$ & $>0.40$ \\
\hline
\end{tabular}

1 Lysolecithin.

${ }^{2}$ Sphingomyelin.

5 Phosphatidylinositol.

${ }^{3}$ Phosphatidylcholine.

${ }^{6}$ Phosphatidylethanolamine.

${ }^{4}$ Phosphatidylserine.

7 Phosphatidic acid. 
available, the mean corpuscular volume of cord blood cells is $20 \%$ greater than that of adult cells, and the total lipid content per cell in cord blood is increased to an even greater degree (27.2\%). Houchin et al. [17] have calculated cell indices and surface area of normal cells and showed that as cell volume increased from $74 \mu^{3}-87 \mu^{3}$ (a change of $17.6 \%$ over initial volume) the surface area increased only from $129 \mu^{2}-140 \mu^{2}$ (a change of $8.5 \%$ of initial area). Similar studies comparing reticulocytes with older cells have shown comparable increments in both surface area and cell volume [38]. The increase in total cell lipid in excess of the increase in cell volume in cord blood erythrocytes could be interpreted as indicating a greater amount of lipid per unit surface area or a change in cell shape allowing for a relatively greater proportion of cell surface per unit volume. The latter possibility would be more in keeping with the unit membrane theory of biological membranes [37]. The return of mean corpuscular volume to adult levels by the second month of life [26] would be accomplished only by replacement of fetal cells with adult type cells and/or by loss of cell membrane units from fetal cells.

The finding of increased amounts of total lipid, phospholipid and cholesterol in cord blood erythrocytes is of particular interest in light of the low level of plasma lipids mentioned above $[6,8,9,42]$. Although there is increasing evidence that membrane lipids exchange rapidly with plasma lipid $[3,21,33]$, the exact mechanism for control of this exchange is unclear. From the cord blood data it would appear that there is no relation between the quantitative amount of total cholesterol and phospholipid in plasma and in red cells. Similar studies on older patients with various forms of plasma hyperlipemia have shown normal or low red cell stromal lipid values [22], a situation exactly opposite to that in the neonate. Variations in red cell phospholipid distribution do appear to reflect plasma phospholipid distribution as seen in abetalipoproteinemia and in certain patients with liver disease $[23,39]$.

The physiologic significance of the erythrocyte stromal lipid pattern of the neonate is difficult to determine. It is largely unknown whether membrane lipid is merely a structural unit or an active participant in membrane function. One possibility is a potential influence on oxygen affinity of the cell. Evidence suggests that a fetal oxygen dissociation curve may be more dependent on the presence of a fetal red cell membrane than on the presence of fetal hemoglobin in the cell [34]. Variations in the membrane structure may therefore allow for differences in permeability of the cell to oxygen [9]. Intrauterine transfusion of the fetus with adult blood for erythroblastosis fetalis has clearly demonstrated that fetal hemoglobin is not essential for intrauterine survival.
The susceptibility of neonatal erythrocytes to hemolysis in dilute hydrogen peroxide solution has been known for many years [14]. Susceptibility of a cell to peroxide hemolysis indicates the rate at which erythrocyte fatty acids can be oxidized and is dependent on a complex balance of prooxidants and antioxidants [16]. The principal erythrocyte pathways for hydrogen peroxide detoxification are dependent on the enzymes catalase and glutathione peroxidase. Both enzymes are present in red cells of the fetus at levels significantly below that of the adult $[15,18]$. A correlation between hydrogen peroxide hemolysis and low red cell catalase levels in the newborn has been shown [25]. Thus, the erythrocytes of neonates have a limited capacity to detoxify peroxides [15]. Peroxidation of unsaturated fatty acids takes place as a nonenzymatic reaction in the presence of oxygen and several prooxidants $\left(\mathrm{Fe}^{++}\right.$, ascorbic acid, glutathione, hemoglobin deivatives) [20]. Since the red cell stroma of the newborn contains an increased amount of total lipid per cell, it could be highly susceptible to peroxide damage due to the limit ability to detoxify this substance. Whether such a mechanism is involved in the group of infants felt to have vitamin $\mathrm{E}$ deficiency as a cause of hemolytic anemia remains to be proven [27]. Nitowsky has noted no correlation between simultaneous peroxide hemolysis test and serum tocopherol levels in unfed neonates [24]. The recent work of Gross et al. [15] suggests that there is no significant hemolysis in adult or fetal cells when exposed to more physiologic levels of hydrogen peroxide in a glucose-containing medium in vitro.

\section{Summary}

Data are presented on the erythrocyte lipid composition of cord blood samples from 42 healthy full-term infants. When compared to erythrocytes of adults, cord blood erythrocytes can be characterized as showing:

1. An increased amount of total lipid, phospholipid and cholesterol per cell.

2. Slight variation in the distribution of individual phosphatides with a tendency toward increased sphingomyelin and combined phosphatidylserine + phosphatidylinositol and a decrease in phosphatidylcholine and phosphatidylethanolamine.

3. Phospholipid fatty acid distribution showing decreased oleic (18:1) and linoleic (18:2) acids and increased palmitic $(16: 0)$, stearic $(18: 0)$, arachidonic $(20: 4)$ and longer chain fatty acids. 


\section{References and Notes}

1. AckMAN, R.G.: Structural correlation of unsaturated fatty acid esters through graphical comparison of gas-liquid chromatographic retention times on a polyester substrate. J. Amer. Oil Chem. Soc. 40: 558 (1963).

2. BARtletr, G.R.: Phosphorous assay in column chromatography. J.biol. Chem. 234: 466 (1959).

3. Basford, J.M.; Glover, J. and Green, C.: Exchange of cholesterol between human beta-lipoproteins and erythrocytes. Biochim. biophys. Acta 84: 764 (1964).

4. Bentley, H.P., Jr.: Erythrocyte phospholipids in the newborn infant. Proc.Soc.exp.Biol. (N.Y.) 111: 591 (1962).

5. Bradlow, B.A.; Lee, J. and Rubenstein, R.: Erythrocyte phospholipids: Quantitative thin layer chromatography in paroxysmal nocturnal haemoglobinuria and hereditary spherocytosis. Brit.J. Haemat. 11: 315 (1965).

6. Brody, S. and Carlson, L. A.: Plasma lipid composition of the newborn with special reference to the distribution of the different lipid fractions. Glin. chim. Acta 7: 694 (1962).

7. Ghiamori, N. and Henry, R.J.: Study of the ferric chloride method for determination of total cholesterol and cholesterol esters. Amer.J.clin. Path. 31: 305 (1959).

8. CHIDA, N.: Paper-electrophoretic analysis of serum lipoproteins of normal infants and children. Tohoku J.exp. Med. 79: 385 (1963).

9. Growley, J.; Ways, P. and Jones, J.W.: Human fetal erythrocyte and plasma lipids. J.clin. Invest. 44: 989 (1963).

10. Dodge, J.T.; Mitchell, G. and Hanahan, D.J.: The preparation and chemical composition of hemoglobin-free ghosts of human erythrocytes. Arch. Biochem. 100: 119 (1963).

11. FARQUHAR, J.W.: Identification and gas-liquid chromatographic behavior of plasmalogen aldehydes and their acetal, alcohol and acetylated alcohol derivatives. J. Lipid Res. 3: 21 (1962).

12. FARQUHAR, J.W.: Human erythrocyte phosphoglycerides. I. Quantification of plasmalogens, fatty acids and fatty aldehydes. Biochim. biophys. Acta 6): 80 (1962).

13. Farquhar, J.W. and Ahrens, E.H., Jr.: Effects of dietary fat on human erythrocyte fatty acid patterns. J. clin. Invest. 42: 675 (1963).

14. Gordon, H.; Nrtowsky, H.M. and Cornblath, M. : Studies of tocopherol deficiency in infants and children. I. Hemolysis of erythrocytes in hydrogen peroxide. Amer.J. Dis. Child. 90: 669 (1955).

2 Pediat. Res., Vol. 2, No. 3 (1968)
15. Gross, R.T.; Bracai, R.; Rudolph, N.; SGhroeDER, E. and Kochen, J.A.: Hydrogen peroxide toxicity and detoxification in the erythrocytes of newborn infants. Blood 29: 481 (1967).

16. Horwirt, M.K. : Vitamin E and lipid metabolism in man. Amer. J. clin. Nutr. 8: 451 (1960).

17. Houchin, D. N.; Munn, J. I. and Parnell, B. L.: A method for the measurement of red cell dimensions and calculation of mean corpuscular volume and surface area. Blood 13: 1185 (1958).

18. Jones, P.E.H. and MaCANCE, R.A.: Enzyme activities in the blood of infants and adults. Biochem. J. 45: 464 (1949).

19. Marks, P.A.; Gellhorn, A. and Kidson, C.: Lipid synthesis in human leukocytes, platelets and erythrocytes. J. biol. Chem. 235: 2579 (1960).

20. Mengel, C.E.; Kann, H.E., Jr. and O'Malley, B.W.: Increased hemolysis after intramuscular iron administration in patients with paroxysmal nocturnal hemoglobinuria. Blood 26: 74 (1965).

21. Mulder, E. and Van Deenen, L.L. M.: Metabolism of red cell lipids. I. Incorporation in vitro of fatty acids into phospholipids from mature erythrocytes. Biochim. biophys. Acta 106: 106 (1965).

22. NeERhout, R.C.: Erythrocyte stromal lipids in hyperlipemic states. J. Lab. clin. Med. 71: 448 (19068).

23. Neerhout, R.C..: Abnormalities of erythrocyte stromal lipids in hepatic disease. J. Lab. clin. Med. 71: 438 (1968).

24. Nrtowsky, H.M.; Cornblath, M. and Gordon, H.H.: Studies of tocopherol deficiency in infants and children. II. Plasma tocopherol and erythrocyte hemolysis in hydrogen peroxide. Amer.J. Dis. Child. 92: 164 (1956).

25. Nitowsky, H.M. and Tildon, J.T.: Studies of tocopherol deficiency in infants and children IIIRelation of blood catalase activity and other factors to hemolysis of erythrocytes in hydrogen peroxide. Amer.J.clin. Nutr. 4: 397 (1956).

26. Oskr, F.A. and Naiman, J.L. : Hematologic problems in the newborn (Saunders, Philadelphia, $\mathrm{Pa}$. 1966).

27. Oski, F.A. and Barness, L.A.: Vitamin E deficiency: A previously unrecognized cause of hemolytic anemia in the premature infant. J. Pediat. 70: 211 (1967).

28. Parker, F. and Peterson, N.F.: Quantitative analysis of phospholipids and phospholipid fatty acids from silica gel thin-layer chromatography. J. Lipid. Res. 6: 455 (1965).

29. Phillips, G. B.: The lipid composition of serum in patients with liver disease. J.clin. Invest. 39: 1639 (1960).

30. Phillips, G.B.: Quantitative chromatographic 
analysis of plasma and red cell lipids in patients with acanthocytosis. J. Lab.clin. Med. 59: 357 (1962).

31. REED, C.F.: Studies of in vivo and in vitro exchange of erythrocyte and plasma phospholipids (Abstract). J.clin. Invest. 38: 1032 (1959).

32. Reed, G. F.; Swisher, S. N.; Marinetti, G.V. and Eden, E. G.: Studies of the lipids of the erythrocyte. I. Quantitative analysis of normal human red blood cells. J.Lab. clin. Med. 56: 281 (1960).

33. Sakagami, T.; Minari, O. and OriI, T.: Interaction of individual phospholipids between rat plasma and erythrocytes. Biochim. biophys. Acta 98: 356 (1965).

34. Schruefer, J.J.P.; Heller, C.J.; Battaglia, F.G. and Hellegers, A.E.: Independence of whole blood and haemoglobin solution oxygen dissociation curves from haemoglobin type. Nature (Lond.) 196: 550 (1962).

35. Skipski, V.P.; Peterson, R.F. and Barclay, M.: Separation of phosphatidylethanolamine, phosphatidylserine and other phospholipids by thin layer chromatography. J. Lipid Res. 3: 467 (1962).

36. Tuffy, P.; Brown, A. and Zuelzer, W.W.: Infantile pyknocytosis. A common erythrocyte abnormality of the first trimester. Amer.J. Dis. Ghild. 98: 227 (1959).

37. VANDENHEuver, F.A.: Structural studies of biological membranes: the structure of myelin. Ann. N.Y.Acad. Sci. 122: 57 (1965).

38. Van Gastel, G.; van den Berg, D.; De Grer, J. and van Deenen, L. L. M.: Some lipid characteristics of normal red blood cells of different age. Brit.J.Haemat. 11: 193 (1965).

39. Ways, P.; Reed, G.F. and Hanahan, D.J.: Red cell and plasma lipids in acanthocytosis. J.clin. Invest. 42: 1248 (1963).

40. Ways, P. and Hanahan, D.J.: Characterization and quantification of red cell lipids in normal man. J.Lipid Res. 5: 318 (1964).

41. WAys, P. and Dong, D.: Etiology of the RBC phospholipid abnormalities in A-betalipoproteinemia (Abstract). Clin. Res. 13: 283 (1965).

42. ZeE, P.: Phospholipids of maternal and cord blood serum. J. Pediat. 67: 949 (1965).

43. Phospholipid standards were kindly supplied by Dr. James F. Mead.

44. Applied Science Laboratories, Inc., State College, Pennsylvania.

45. The author is indebted to Drs. John W. FARQuHAR, JAMES F. MEAD, and M. Eugene LAHEY for guidance in developing the methodology used in this study. The technical assistance of Mrs. ERMA SHANkLIN is greatly appreciated.

46. This study was supported in part by US Public Health Service Grant 5-R01-HD02124-02 and 1-SOL-FR05354.

47. Requests for reprints should be addressed to: Robert C.Neerhout, M.D. Department of Pediatrics, University of California School of Medicine, The Center for the Health Sciences, Los Angeles, Cal. 90024 (USA). 